\title{
APROXIMACIONES A LOS DOCUMENTOS DE LA QUEBRADA DE HUMAHUACA, UN CAMINO DE EXPLORACIÓN DEL ARCHIVO DE LA PRELATURA DE HUMAHUACA
}

\section{APPROACHES TO DOCUMENTS OF THE QUEBRADA DE HUMAHUACA, A PATH OF EXPLORATION FILE OF THE PRELATURE OF HUMAHUACA}

\author{
Diego CITTERIO \\ UNIHR-ISHIR-CONICET
}

Resumen: El trabajo de catalogación y digitalización del Archivo Histórico de la Prelatura de Humahuaca, nos sitúa ante una masa documental, casi sin uso para la investigación histórica. Debido a razones de organización, este acervo documental se veía limitado a la consulta de los investigadores. El desarrollo del proyecto "Documenta", nos permitirá conocer el contenido de dicho archivo, acercarnos a esos documentos para la consulta y producción científica.

Palabras clave: Prelatura de Humahuaca, archivo, catalogación, digitalización.

\begin{abstract}
The work of cataloging and digitizing the Historical Archive of the Prelature of Humahuaca, presents us with documentary mass, almost unused for historical research. Due to organizational reasons, this documentary heritage was limited to consultation of researchers. The development of "Documenta" project will allow us to know the contents of that file, get closer to these documents for consultation and scientific production.
\end{abstract}

Keywords: Prelature of Humahuaca, archive, cataloging, digitizing.

\section{LA QUEBRADA Y LA PRELATURA DE HUMAHUACA. BREVE SÍNTESIS HISTÓRICA}

La Quebrada de Humahuaca constituye uno de los accidentes geográficos más importantes del noroeste argentino: se extiende a lo largo de unos $180 \mathrm{kms}$, con una orientación norte-sur. Enmarcada por cordones montañosos de poca altu- 
ra, su parte superior — casi sobre la Puna — es la más alta y abierta, mientras que la sección media resulta más encajonada y angosta. El río Grande nace en el abra de Tres Cruces en la Puna, baja por el fondo de la Quebrada, estrechándose en algunos tramos, y al llegar al valle de Jujuy, se desvía para formar el rio de San Francisco que desemboca en el Bermejo.

Su vegetación refleja los cambios climáticos y altitudinales que va sufriendo a lo largo de su trazado. Las zonas más septentrionales y la porción media muestran las variedades típicas de la pre-puna, con predominio de la estepa arbustiva: churquis, molles, y cactáceas. En la última porción del Volcán, ya al sur, la vegetación comienza a hacerse más copiosa y alternan arbustos y pastizales; en los faldeos de mayor altura, aparecen arboles más exuberantes que indican los inicios del bosque subtropical: cedro, lapacho, tipa blanca, palo amarillo ${ }^{1}$.

Esta abundancia de recursos, junto a las posibilidades de comunicación y acceso a las otras regiones, fue uno de los principales atractivos para su temprano poblamiento. En efecto, cuando llegaron los europeos en el siglo XVI, era una de las regiones más densamente pobladas del actual noroeste argentino.

La Quebrada de Humahuaca fue escenario de diversas batallas por la independencia y territorio de disputa entre el ejército realista y el ejército del norte (Cangrejos y Humahuaca 1814). Durante 15 años, los habitantes de la Quebrada soportan ocupaciones, batallas, el establecimiento de centros de operaciones tanto del ejército del Norte como el Realista.

A principios del siglo XX el impacto en la Quebrada lo produce el paso del Ferrocarril Central Norte a Bolivia. El triunfo del Senador T. Pérez sobre la elite salteña produjo la transición del comercio de mulares y vacunos al funcionamiento del ferrocarril. Se desarrollaron y fortalecieron numerosas poblaciones relacionadas al servicio ferroviario (León, Maimará, Iturbe, Volcán). En la década de 1960 y 1970 se amplia y pavimenta la ruta 9, siendo esta la vía utilizada con el fin del ferrocarril en los ' $90^{2}$.

En las últimas décadas se observa una tendencia de ciertos mercados a valorar los productos culturales tradicionales ocasionando una reactivación de la producción artesanal. Sumado a esto que la región fue declarada "Patrimonio Cultural y Natural de la Humanidad" por la Organización de las Naciones Unidas para la Educación, la Ciencia y la Cultura (Unesco) en 2003.

${ }^{1}$ G. SICA, M. T. BOVI y L. MALLAGRAY, "La Quebrada de Humahuaca: de la colonia a la actualidad", en Jujuy en la Historia. De la colonia al siglo XX, San Salvador de Jujuy, 2010, pp. 351-372.

${ }^{2}$ G. SICA, M. T. BOVI y L. MALLAGRAY, “La Quebrada de Humahuaca...”, pp. 351-372. 
El boom del turismo a reconfigurado a los pueblos de la Quebrada, hoy podemos observar la llegada de inversiones inmobiliarias que se radican en estos pueblos. Provocando la superpoblación en las localidades, la ocupación de sitios con evidente interés arqueológico y elevando los precios de la tierra para los pobladores del lugar.

\section{LA PRELATURA DE HUMAHUACA}

La Prelatura de Humahuaca es una jurisdicción eclesiástica existente en el territorio de la República Argentina. Su sede episcopal se encuentra en la ciudad de Humahuaca.

Creada el 8 de setiembre de 1969, con la bula "Praeclarisima exempla", de Pablo VI. Comprende, en la provincia de Jujuy, los departamentos de Cochinoca, Humahuaca, Rinconada, Santa Catalina, Susques y Yavi. En la provincia de Salta, la parte occidental de los departamentos de Iruya y Santa Victoria.

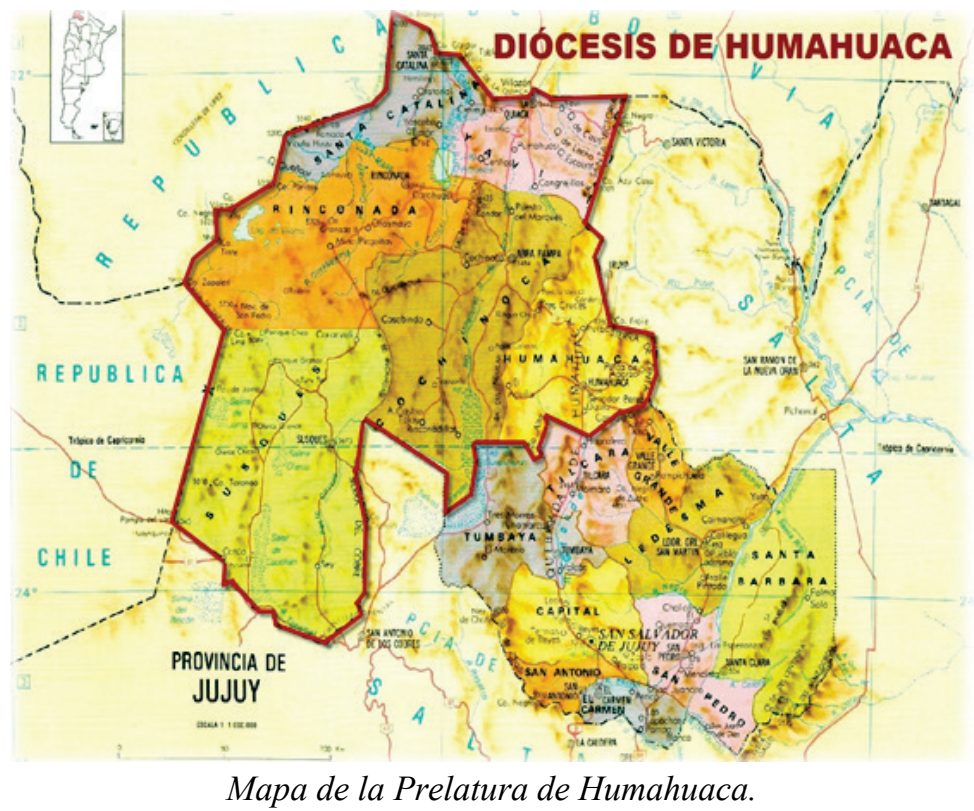

Fuente: http://horadeverdad.blogspot.com.ar/2012/01/obispos-argentinos-1-provincia.html.

El primer prelado de Humahuaca fue el R.P. José María Márquez Bernal, claretiano español, a quien el Pontífice nombró Administrador Apostólico, sin carácter episcopal en la misma fecha de la creación de la Prelatura. El mismo papa lo designó Prelado de Humahuaca elevándolo a la dignidad de obispo titular de Capo de la Foresta el 10 de octubre de 1973, y fue consagrado el 25 de noviembre de ese año. El 3 de noviembre de 1977 el Santo Padre lo nombró obispo-prelado 
de Humahuaca. Renunció por razones de salud el 20 de febrero de 1991. Falleció el 17 de marzo de 1995 en Sevilla, España.

El segundo Prelado de Humahuaca es el actual, Mons. Pedro María Olmedo Rivero, claretiano español como su predecesor. Tras ser elegido Administrador diocesano por la renuncia de Mons. Márquez Bernal, Juan Pablo II lo nombró obispo-prelado de Humahuaca el 7 de julio de 1993. Fue ordenado obispo el 25 de setiembre de ese año y desde el 26 de noviembre gobierna pastoralmente la Prelatura humahuaqueña.

\section{EL ARCHIVO DE LA PRELATURA DE HUMAHUACA}

En primer lugar, debemos señalar que un primer aporte a la digitalización de los archivos parroquiales lo ha realizado la Iglesia de Jesucristo de los Santos de los últimos días (conocido popularmente como Mormones) a través del portal Family Search donde se encuentra una inmensa indexación de registros bautismales y parroquiales durante ya casi cien años. Si bien el portal Family Search no tiene la totalidad de los registros (bautismales, casamientos y defunciones) el universo que abarca es muy amplio.

Para el caso de la provincia de Jujuy y específicamente la Puna y la Quebrada de Humahuaca encontramos los siguientes datos.

\begin{tabular}{|c|c|c|c|c|c|}
\hline Parroquia & Bautismos & Confirmaciones & Matrimonios & Defunciones & Cofradías \\
\hline \multirow{5}{*}{ Cochinoca } & $1776-1860$ & $1859-1892$ & $1773-1816$ & $1773-1852$ & \\
\hline & $1892-1901$ & $1897-1927$ & $1829-1841$ & $1855-1928$ & \\
\hline & $1901-1912$ & & $1845-1889$ & & \\
\hline & $1912-1916$ & & 1891-1931 & & \\
\hline & 1916-1921 & & & & \\
\hline \multirow[t]{9}{*}{ Humahuaca } & $1823-1827$ & $1840-1872$ & $1734-1745$ & $1799-1816$ & 1664-1788 \\
\hline & $1827-1843$ & $1900-1905$ & $1745-1756$ & $1823-1840$ & \\
\hline & $1849-1888$ & $1905-1928$ & $1765-1783$ & $1780-1867$ & \\
\hline & $1858-1872$ & & & $1867-1871$ & \\
\hline & $1872-1891$ & & & & \\
\hline & 1891-1898 & & & & \\
\hline & 1898-1906 & & & & \\
\hline & 1906-1915 & & & & \\
\hline & $1915-1922$ & & & & \\
\hline Vallegrande & & & & 1874-1913 & \\
\hline \multirow[t]{5}{*}{ Rinconada } & $1781-1827$ & & $1822-1856$ & 1809-1928 & \\
\hline & $1809-1827$ & & $1856-1872$ & & \\
\hline & $1827-1843$ & & $1873-1889$ & & \\
\hline & $1843-1856$ & & 1891-1905 & & \\
\hline & $1856-1864$ & & 1908-1928 & & \\
\hline
\end{tabular}


APROXIMACIONES A LOS DOCUMENTOS DE LA QUEBRADA DE HUMAHUACA...

\begin{tabular}{|l|l|l|l|l|l|}
\hline & $1864-1872$ & & & & \\
\hline & $1873-1924$ & & & & \\
\hline $\begin{array}{l}\text { Santa } \\
\text { Catalina }\end{array}$ & $1773-1789$ & $1881-1897$ & $1752-1773$ & $1794-1803$ & \\
\hline & $1789-1805$ & $1915-1970$ & & $1806-1848$ & \\
\hline & 1805 & & & $1849-1889$ & \\
\hline & $1806-1884$ & & & $1892-1893$ & \\
\hline & $1881-1904$ & & & $1899-1932$ & \\
\hline & $1904-1907$ & & & & \\
\hline & $1907-1914$ & & & & \\
\hline & $1914-1921$ & & & & \\
\hline & $1843-1859$ & $1881-1897$ & & $1875-1887$ & \\
\hline & $1859-1871$ & $1893-1942$ & & $1843-1905$ & \\
\hline & $1871-1872$ & & & & \\
\hline & $1872-1875$ & & & & \\
\hline & $1887-1898$ & & & & \\
\hline & $1898-1912$ & & & & \\
\hline & $1912-1916$ & & & & \\
\hline & $1916-1919$ & & & & \\
\hline & $1919-1920$ & & & & \\
\hline & $1920-1922$ & & & & \\
\hline
\end{tabular}

Cuadro: Parroquias y documentos en Family Search.

Fuente en base a: familysearch.org (consultada el 19/02/2015).

En la prelatura encontramos también el fondo documental perteneciente a dicha Prelatura y a OCLADE (Obra Claretiana para el Desarrollo) una fundación con más de 30 años de trabajo en la Quebrada y la Puna, desarrollando tareas de promoción humana en las comunidades campesinas.

Pero el inmenso caudal de información que más nos interesa es el fondo documental histórico que abarca documentos de los siglos XVII, XVIII, XIX y XX.

El primer trabajo que hemos realizado es una catalogación básica, agrupando la documentación por parroquias y no por párrocos o por fechas como anteriormente lo había realizado un sacerdote claretiano. Este criterio que adoptamos fue para establecer el origen del documento. Donde fue escrito y elaborado. Es necesario aclarar que este fondo documental histórico está incompleto y dividido en 3 repositorios uno es el de la Prelatura, el otro es el archivo del Obispado de Jujuy y el tercero es el archivo del Obispado de Salta.

De esa primera catalogación pudimos conformar un universo de 11 parroquias divido en 16 cajas que contienen toda esta masa documental; Humahuaca, Jujuy, Iruya, Yavi, Rinconada, Cochinoca, Casabindo, Santa Catalina, Vallegrande, Puna, y Abra Pampa. Muchas de ellas fundadas en el periodo colonial. Para el caso de la iglesia de Yavi actuó como capilla palatina respecto de la Casa de los Marqueses de Tojo. La fecha de su terminación es el año 1707. Para el caso de 
Cochinoca, fue fundada como parroquia en 1720, aunque ya existía una capilla desde comienzos del siglo XVII. En el caso de la parroqui Nuestra Señora de la Candelaria, de Humahuaca (Catedral) fue fundada hacia 1600.

\section{EL FONDO DOCUMENTAL HISTÓRICO}

Los documentos que encontramos son muy diversos y variados. Conformando un total de 300 expedientes, donde algunos contienen un solo folio y otros llegan a los 50 o 60 folios. Obteniendo hasta el momento 4600 capturas en imágenes de estos documentos.

Se han encontrado pedimentos de matrimonios (solicitud de permiso para casarse), testamentarias (documentación que registra bienes de personas que han instituido algún sacerdote como albacea ${ }^{3}$, comunicaciones del Obispo de Salta para los siglos XVIII y XIX, pleitos y conflictos de los sacerdotes (aquí encontramos diferencias entre el clero disputando bienes económicos, como también problemas con los fieles e incluso con los Marqueses de Tojo), Libros de Fabricas (donde se asientan y regitran los ingresos por limosnas y servicios parroquiales y donde se anotan los egresos por los gastos ocasionados), Cartas pastorales, inventarios parroquiales, Autos de visitas del Deán Funes, Juicios criminales contra algunos curas, Juicios con el Marques de Tojo, distintas notificaciones de los poderes judiciales, legislativos y ejecutivos durante la primer mitad del siglo XX.

\section{DOCUMENTOS}

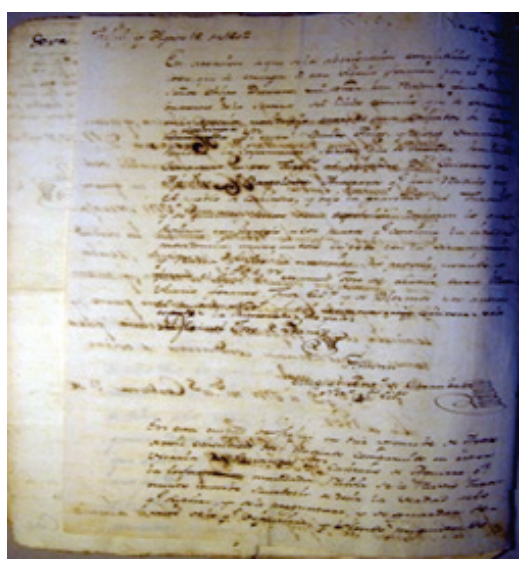

Siglo XVIII (Casabindo).

\footnotetext{
${ }^{3}$ Diccionario Real Academia Española, m. y f. Persona encargada por el testador o por el juez de cumplir la última voluntad del fallecido, custodiando sus bienes y dándoles el destino que corresponde según la herencia.
} 


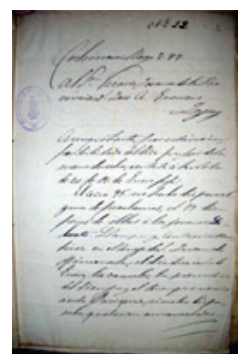

Siglo XIX (Cochinoca).
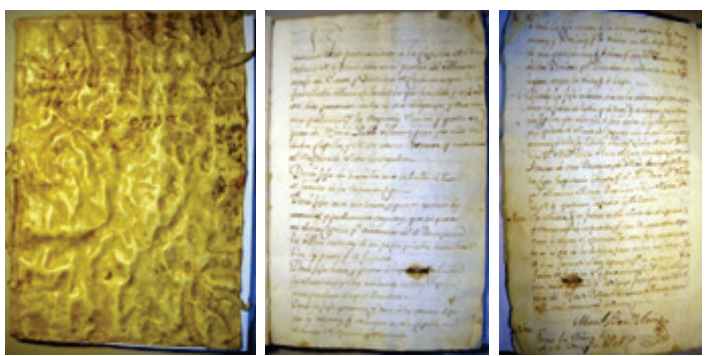

Libros de Fábrica, Cochinoca, siglo XVIII ${ }^{4}$.

\section{DOCUMENTA: UN PROYECTO A LARGO PLAZO}

La propuesta de Documenta intenta situar a la Unidad de Investigación en Historia Regional (UNIHR) en el contexto regional prestando un servicio de catalogación y digitalización de archivos históricos privados o públicos.

Tiene como objetivo establecer lazos con personas, instituciones de la esfera privada o estatal para brindar el apoyo a la conservación de documentos históri$\cos$.

Siguiendo el espíritu y los objetivos del Centro de Documentación y Digitalización del ISHIR entendemos que; "el historiador trabaja sobre un objeto esquivo del que solo quedan ruinas. Desordenadas, en inminente destrucción, fragmentarias, las ruinas son a su vez la muestra cabal de que no hay suceso sin exceso. Dos acciones, son, pues, posibles en esta búsqueda por recuperar el pasado, mientras somos empujados por el huracán del presente. Por un lado, la preservación de las ruinas. La conservación de estado y las condiciones de cada guijarro, de cada montículo, de cada grano de polvo. Esta es la tarea de archivo. Por otro, la reconstitución de la serie en que cada fragmento se encuentra. A qué piedra mayor per-

\footnotetext{
${ }^{4}$ Hemos elegido estas imágenes para que los lectores tuvieran una aproximación a qué tipo de fuentes y documentos nos referimos. Son un escaso ejemplo de la variedad con la que hemos trabajado. En ellos la información que se encuentra nos muestra el inicio de un libro de fábrica donde el sacerdote da cuenta de los bienes que administra.
} 
tenecen estos escombros, reconstruir el edificio detrás de cada demolición. Esta es la tarea de documentación. Una tercera acción, de la cual las anteriores son sus insumos principales. La reconstitución de las series de series, de los paisajes complejos, de la ciudad tras la catástrofe. Ese es el trabajo de la historia"5.

Nuestro aporte con documenta es vincularnos con las distintas realidades culturales de la región del NOA (entendiendo a Salta, Tucumán, Jujuy).

Las tareas desarrolladas en la Prelatura de Humahuaca tienen tres momentos, donde todavía estamos ejecutando el segundo paso.

En los meses de noviembre y diciembre de 2015 se llevó adelante una catalogación mínima, para organizar el material y establecer criterios de clasificación.

Durante los meses de enero, febrero, marzo de 2015 se llevó a cabo el proceso de fotografiado (digital) de los expedientes. Tarea que se realiza dos veces por semana.

$\mathrm{Y}$ en los meses de abril y mayo la clasificación de estas capturas para ya dejarlas en los soportes digitales de la Prelatura y de UNIHR-ISHIR-CONICET.

${ }^{5}$ M. BONAUDO y G. FERRAGUTTI, Proyecto de Fortalecimiento del Centro de Documentación y Digitalización del Ishir, Rosario, 2014. 